\title{
Temporal and Spatial Differentiation of Innovation Quality in China
}

\author{
Jinling Li \\ School of Business, Nanjing Normal University, Nanjing, China \\ Email: 13236507611@163.com
}

How to cite this paper: Li, J. L. (2020). Temporal and Spatial Differentiation of Innovation Quality in China. Open Journal of Social Sciences, 8, 117-126.

https://doi.org/10.4236/jss.2020.810009

Received: September 17, 2020

Accepted: October 17, 2020

Published: October 20, 2020

Copyright $\odot 2020$ by author(s) and Scientific Research Publishing Inc. This work is licensed under the Creative Commons Attribution International License (CC BY 4.0).

http://creativecommons.org/licenses/by/4.0/ (c) (i) Open Access

\begin{abstract}
This paper constructs a comprehensive evaluation system of innovation quality from the process of innovation input-output, and calculates the comprehensive evaluation value of innovation quality in various regions of China by using the entropy method. This paper makes a dynamic comprehensive analysis of the innovation quality of the eastern, central, and western regions of China from 2008 to 2017. The results show that although China's economy has been growing and innovation has increasingly become the focus of attention of the government and enterprises, the overall quality of innovation is not high, and there are obvious temporal and spatial differences. The innovation quality of the central and western regions is significantly lower than that of the eastern regions, and the differences show an expanding trend. And in recent years, the overall level of innovation quality in China has shown a downward trend.
\end{abstract}

\section{Keywords}

Innovation Quality, Spatiotemporal Differentiation, Entropy Method, Comprehensive Evaluation Index

\section{Introduction}

Since the reform and opening-up, China's economy has been growing rapidly. Among them, the level of scientific and technological innovation is the most important factor for a country's economy to take off. As early as the 1980s, Comrade Deng Xiaoping put forward that "science and technology are the first productive forces", which is enough to illustrate the importance that the Chinese government attaches to scientific and technological innovation. Over the years, the research in the field of innovation has experienced a process from the initial product and service innovation to the process and business innovation, and then 
to the comprehensive innovation and open innovation. This also shows that research on innovation has always been the focus of academic research. However, it is undeniable that there is still an obvious gap between China's innovation ability and that of developed countries. How to improve the innovation ability needs to focus on the research and inspection of innovation quality.

\section{Literature Review}

The discussion on the measurement index and measurement method of innovation quality has always been the focus of scholars' research. Haner (2002) first proposed the concept of innovation quality. He believed that innovation quality should be measured from three dimensions: product and service, process, and enterprise. After that, most scholars focus on innovation performance or innovation efficiency, patent quantity, or patent quality. Tong \& Frame (1994) believed that the quality and quantity of patents can reflect the ability of technological innovation. Zhang et al. (2011) believed that innovation quality is an important aspect of innovation ability. Among them, the quality of innovation is best reflected by the number of patents, the number of patent grants, the authorization rate, and the length of the payment period. Yang et al. (2007) studied the current situation of innovation quality of China's high-tech enterprises and found that innovation quality is the comprehensive embodiment of enterprise business performance in the final product and service quality, operation process quality, and management quality. Sun \& Song (2012) believe that the index of industrial innovation is per-capita patent output. Li et al. (2011) researched on innovation quality focuses on the comparison between new product sales revenue as innovation output and R \& D capital stock and personnel input as innovation input. However, scholars also put forward different views on this. $\mathrm{Lu}$ (2011) thought that research and development investment is not the only way for enterprises to develop new products, and the input-output based on research and development can not reflect the overall innovation efficiency of enterprises. Although the main business income, the number of patents, the number of research and development personnel, and expenditure can reflect part of the innovation quality level, these factors do not fully explore the "essence" of innovation quality, so they can not accurately reflect the innovation quality. Innovation quality should be reflected in the efficiency of innovation input-output and the benefit of innovation cost income. Based on this, this paper innovatively establishes a comprehensive index evaluation system of innovation input, output efficiency, and innovation cost-benefit efficiency.

According to the analysis of existing research results, only a few scholars have explored the difference of innovation quality between eastern and central and Western China from the perspective of space (Ma et al., 2014), and no scholar has explored the difference of innovation quality in China from the perspective of space and time. However, since the reform and opening-up, China's innovation ability has been continuously improved, and the innovation quality has both 
spatial and temporal differences. Based on this analysis, this paper will comprehensively explore the differences between regional innovation quality in China from the perspective of space and time.

\section{Evaluation Index System of Innovation Quality}

The evaluation index system is the key element to measure the quality innovation and innovation quality level, which should be under the principles of scientificity, rationality, feasibility, and adaptability. Therefore, this paper will draw lessons from the existing innovation performance evaluation system, and according to the above principles, construct a three-level comprehensive evaluation of innovation quality from two dimensions of innovation input-output efficiency and innovation achievement transformation efficiency. The index system is shown in Table 1.

\subsection{Construction of Innovation Quality Evaluation Index}

The process of innovation input and output reflects the quality of the innovation process. The activity basis of innovation is its process, so the higher the innovation process, the better the quality of innovation can be guaranteed. Innovation input-output efficiency is based on the input-output of innovation elements. The higher the utilization and utility of innovation elements, the better the quality of innovation. Based on the input-output efficiency, we use the new product $\mathrm{R} \& \mathrm{D}$ investment as one of the indicators of innovation quality efficiency. Besides, the invention patent application rate and $\mathrm{R} \& \mathrm{D}$ expenditure per capita can also reflect the level and quality of innovation. The invention patent application rate and per capita R \& D expenditure are also taken as indicators to measure the utility of innovation output.

The process of transforming the efficiency of innovation achievements reflects the quality of innovation benefits. Good economic benefits of innovation can further stimulate innovation behavior and bring a positive cycle for innovation.

Table 1. Evaluation index system of innovation quality.

\begin{tabular}{|c|c|c|c|c|c|}
\hline $\begin{array}{l}\text { First level } \\
\text { indicator }\end{array}$ & $\begin{array}{l}\text { Secondary } \\
\text { indicators }\end{array}$ & Level three indicators & $u_{i j}$ & unit & type \\
\hline \multirow{5}{*}{$\begin{array}{c}\text { Innovation } \\
\text { quality } \\
U\end{array}$} & The & New product funding & $u_{11}$ & Ten thousand yuan & + \\
\hline & $\begin{array}{l}\text { innovation } \\
\text { input and }\end{array}$ & $\begin{array}{l}\text { Invention patent } \\
\text { application rate }\end{array}$ & $u_{12}$ & $\%$ & + \\
\hline & $\begin{array}{c}\text { output } \\
\text { efficiency }\end{array}$ & $\begin{array}{c}\text { R \& D expenditure } \\
\text { per capita }\end{array}$ & $u_{13}$ & Ten thousand yuan & + \\
\hline & $\begin{array}{c}\text { Innovation } \\
\text { achievement }\end{array}$ & $\begin{array}{c}\text { The ratio of new products } \\
\text { to the number of } \\
\text { invention patents }\end{array}$ & $u_{14}$ & $\%$ & + \\
\hline & $\begin{array}{c}\text { transformation } \\
\text { efficiency }\end{array}$ & $\begin{array}{l}\text { High-tech new products } \\
\text { accounted for the main } \\
\text { business income ratio }\end{array}$ & $u_{15}$ & $\%$ & + \\
\hline
\end{tabular}


The efficiency index of innovation achievement transformation is based on the efficiency of cost and income. When the economic benefit of innovation is higher, that is, the efficiency of achievement transformation is higher. In this paper, the proportion of new product sales revenue in high-tech industry profits and the number of new products in the number of invention patents is used as the economic benefit index of innovation. Innovatively put forward through the ratio of the number of new products to the number of invention patents, we can see the efficiency of the transformation of invention patents into products.

\subsection{Determination Method of the Comprehensive Evaluation Value of the Index}

In this paper, the entropy method is used to confirm the weight, and the entropy value is used to judge the dispersion degree of an index. The greater the dispersion degree of the index, the greater the influence of the index on the comprehensive evaluation, and vice versa. According to the method of Liu \& Lin (2018), the importance of each evaluation index can be scientifically reflected according to the influence of indicators on the overall system.

There are $n$ evaluation objects and $m$ evaluation indexes with the value of $u_{i j}$.

\subsubsection{Data Processing}

The extreme value processing method is adopted to process the data dimensionless, and the data is translated to solve the problem of $u_{i j}=0$. after the extreme value processing and to ensure $u_{i j}>0$. At the same time, to maintain the difference and authenticity of the original data, the amplitude of the translation is set to 0.1 . If the evaluation index is positive, then the Formula (1), and the inverse index is Formula (2). Since the evaluation indexes in this paper are all positive indexes, Formula (1) is adopted.

$$
\begin{aligned}
& u_{i j}^{*}=\left(\frac{u_{i j}-u_{\min }}{u_{\max }-u_{\min }}\right) \times 0.9+0.1 \\
& u_{i j}^{*}=\left(\frac{u_{\max }-u_{i j}}{u_{\max }-u_{\min }}\right) \times 0.9+0.1
\end{aligned}
$$

Among them, $u_{i j}$ is the dimensionless value of the $j$ index of the $i$ evaluation object, $i=1,2,3, \cdots, n ; j=1,2,3, \cdots, m . u_{\max }=\max \left\{u_{i j}\right\}, u_{\min }=\max \left\{u_{i j}\right\}$.

\subsubsection{Calculate the Feature Ratio of the ith Evaluated Object on the $j$ th} Evaluation Index

$$
p_{i j}=u_{i j}^{*} / \sum_{i=1}^{n} u_{i j}^{*}
$$

\subsubsection{Calculate the Entropy of the $j$ th Term}

$$
e_{j}=\frac{-1}{\ln n} \sum_{i=1}^{n} p_{i j} \ln \left(p_{i j}\right)
$$

Among them, $0 \leq e_{j} \leq 1$. The larger the entropy value $e_{j}$, the smaller the information provided by the indicator, and the smaller the role it plays. 
3.2.4. Calculate the Difference Coefficient of the $j$ th Evaluation Index

$$
g_{j}=1-e_{j}
$$

Among them, $0 \leq g_{j} \leq 1$, the greater the entropy $g_{j}$, the greater the importance of the comprehensive evaluation index system.

\subsubsection{Calculate the Weight Coefficient of the $j$ th Evaluation Index}

$$
w_{j}=g_{j} / \sum_{j=1}^{m} g_{j}
$$

\subsubsection{Comprehensive Evaluation Value of $\boldsymbol{n}$ Evaluation Objects}

$$
u_{j}=\sum_{j=1}^{m}\left(w_{j} \times u_{i j}^{*}\right)
$$

\section{The Innovation Quality of the Difference of Time and Space}

Table 2 is the result of the 2008-2017 comprehensive evaluation of China's regional innovation quality indicators. According to the data in Table 2, according to the geographical position is divided into eastern, central, and western three areas, to examine the spatial difference of regional innovation quality, Figure 1 for the eastern, central, and western China.

From the empirical results of the innovation quality of China's regions from 2008 to 2017, we can see that the spatial and temporal evolution of innovation quality in China mainly shows the following characteristics. Firstly, during the inspection period, the quality of innovation in various provinces and cities in China has shown relatively obvious growth. Among them, the overall growth rate of innovation quality in the eastern region is the most obvious compared to the central and western regions. Among them, Jiangsu, Zhejiang, Shanghai, Guangdong, and Shandong, the innovation quality level of these five regions exceeds 0.5. This is because these provinces and regions have developed economies, innovation depends on a strong economic background, and many high-level universities in China and research institutes are located in these places. Therefore, scientific research talents and innovation output are in a leading position in terms of quantity and quality. Thanks to a large amount of R \& D and innovation investment and the concentration of $\mathrm{R} \& \mathrm{D}$ talents, the quality of innovation in these regions leading the national level. From the perspective of innovation input and output efficiency, the number of invention patents, new product

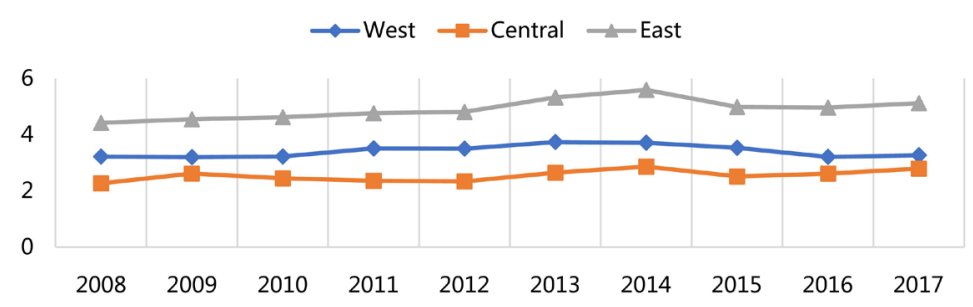

Figure 1. Trends of innovation quality in eastern, central, and western China. 
Table 2. Comprehensive evaluation value of innovation quality in different regions of China.

\begin{tabular}{|c|c|c|c|c|c|c|c|c|c|c|c|}
\hline Region & 2017 & 2016 & 2015 & 2014 & 2013 & 2012 & 2011 & 2010 & 2009 & 2008 & Mean \\
\hline Bejing & 0.406 & 0.404 & 0.431 & 0.468 & 0.446 & 0.430 & 0.424 & 0.385 & 0.384 & 0.470 & 0.425 \\
\hline Tianjin & 0.416 & 0.400 & 0.395 & 0.478 & 0.475 & 0.447 & 0.440 & 0.450 & 0.432 & 0.472 & 0.441 \\
\hline Hebei & 0.335 & 0.285 & 0.312 & 0.397 & 0.341 & 0.307 & 0.280 & 0.288 & 0.298 & 0.262 & 0.310 \\
\hline Shanxi & 0.248 & 0.232 & 0.223 & 0.274 & 0.282 & 0.257 & 0.240 & 0.232 & 0.253 & 0.233 & 0.247 \\
\hline Neimenggu & 0.266 & 0.254 & 0.252 & 0.311 & 0.286 & 0.289 & 0.305 & 0.335 & 0.333 & 0.253 & 0.288 \\
\hline Liaoning & 0.372 & 0.367 & 0.368 & 0.453 & 0.458 & 0.433 & 0.414 & 0.460 & 0.435 & 0.334 & 0.409 \\
\hline Jining & 0.352 & 0.330 & 0.309 & 0.338 & 0.294 & 0.255 & 0.323 & 0.298 & 0.293 & 0.344 & 0.313 \\
\hline Heilongjiang & 0.265 & 0.244 & 0.234 & 0.276 & 0.254 & 0.216 & 0.248 & 0.236 & 0.263 & 0.214 & 0.245 \\
\hline Shanghai & 0.509 & 0.487 & 0.505 & 0.574 & 0.539 & 0.524 & 0.509 & 0.482 & 0.451 & 0.453 & 0.503 \\
\hline Jiangsu & 0.587 & 0.589 & 0.608 & 0.671 & 0.663 & 0.613 & 0.604 & 0.567 & 0.541 & 0.541 & 0.598 \\
\hline Zhejiang & 0.678 & 0.635 & 0.573 & 0.607 & 0.560 & 0.456 & 0.434 & 0.381 & 0.386 & 0.441 & 0.515 \\
\hline Anhui & 0.429 & 0.389 & 0.358 & 0.381 & 0.365 & 0.332 & 0.339 & 0.311 & 0.297 & 0.262 & 0.346 \\
\hline Fujian & 0.305 & 0.301 & 0.300 & 0.338 & 0.332 & 0.296 & 0.301 & 0.281 & 0.292 & 0.297 & 0.304 \\
\hline Jiangxi & 0.359 & 0.362 & 0.328 & 0.409 & 0.332 & 0.313 & 0.289 & 0.315 & 0.353 & 0.310 & 0.337 \\
\hline Shandong & 0.533 & 0.542 & 0.578 & 0.652 & 0.591 & 0.519 & 0.497 & 0.522 & 0.520 & 0.417 & 0.537 \\
\hline Henan & 0.310 & 0.291 & 0.280 & 0.331 & 0.308 & 0.238 & 0.258 & 0.245 & 0.259 & 0.254 & 0.278 \\
\hline Hubei & 0.408 & 0.380 & 0.393 & 0.425 & 0.396 & 0.356 & 0.332 & 0.316 & 0.317 & 0.322 & 0.364 \\
\hline Hunan & 0.430 & 0.391 & 0.395 & 0.438 & 0.422 & 0.375 & 0.339 & 0.502 & 0.584 & 0.333 & 0.421 \\
\hline Guangdong & 0.723 & 0.673 & 0.645 & 0.631 & 0.610 & 0.540 & 0.573 & 0.532 & 0.544 & 0.512 & 0.598 \\
\hline Shanxi & 0.309 & 0.304 & 0.305 & 0.373 & 0.383 & 0.314 & 0.328 & 0.323 & 0.340 & 0.276 & 0.325 \\
\hline Hainan & 0.264 & 0.291 & 0.277 & 0.329 & 0.316 & 0.253 & 0.292 & 0.282 & 0.272 & 0.226 & 0.280 \\
\hline Chongqing & 0.485 & 0.450 & 0.449 & 0.451 & 0.383 & 0.378 & 0.395 & 0.327 & 0.280 & 0.403 & 0.400 \\
\hline Sichuan & 0.271 & 0.275 & 0.278 & 0.315 & 0.308 & 0.265 & 0.288 & 0.274 & 0.293 & 0.318 & 0.289 \\
\hline Guizhou & 0.227 & 0.242 & 0.214 & 0.224 & 0.220 & 0.240 & 0.266 & 0.268 & 0.297 & 0.239 & 0.244 \\
\hline Yunnan & 0.261 & 0.276 & 0.248 & 0.299 & 0.275 & 0.235 & 0.231 & 0.233 & 0.241 & 0.225 & 0.252 \\
\hline Xizang & 0.194 & 0.143 & 0.373 & 0.143 & 0.379 & 0.440 & 0.415 & 0.215 & 0.207 & 0.416 & 0.292 \\
\hline Shaanxi & 0.256 & 0.261 & 0.274 & 0.317 & 0.300 & 0.264 & 0.287 & 0.288 & 0.296 & 0.273 & 0.282 \\
\hline Gansu & 0.202 & 0.213 & 0.252 & 0.328 & 0.277 & 0.256 & 0.253 & 0.208 & 0.204 & 0.213 & 0.241 \\
\hline Qinghai & 0.282 & 0.220 & 0.273 & 0.238 & 0.241 & 0.219 & 0.211 & 0.239 & 0.215 & 0.185 & 0.232 \\
\hline Ningxia & 0.308 & 0.322 & 0.322 & 0.360 & 0.383 & 0.339 & 0.306 & 0.295 & 0.295 & 0.246 & 0.318 \\
\hline Xinjiang & 0.213 & 0.257 & 0.298 & 0.363 & 0.310 & 0.271 & 0.233 & 0.227 & 0.206 & 0.182 & 0.256 \\
\hline
\end{tabular}

expenditures, and per capita R \& D expenditures in these places is all high. From the perspective of the transformation efficiency of innovation achievements, the ratio of the number of new products to the number of invention patents, and the ratio of new product revenue to high-tech main business revenue in these re- 
gions are also at the leading level. From the perspective of the central region, Hubei, Anhui, Hunan and other provinces have higher innovation quality. The reason is that the economy of these regions is developing well in the central region, and there are more scientific research institutions in the region, which provide talents and technical reserves for innovation. However, there is still a big gap compared with the eastern region.

From the perspective of western China, the quality of innovation in Chongqing is in the leading position in the western region. The level of innovation quality in most other regions of the west is relatively low. This is because the western region lacks funds and talents for scientific research and innovation, and the number of patent ownership and applications is far behind other regions.

In terms of time, although the overall innovation quality level of the eastern, central, and western regions showed an upward trend from 2008 to 2017, in 2014 , the eastern and western regions had the highest level of innovation quality. During 2014-2017, the innovation quality showed a downward trend. The stamina of innovation quality is insufficient.

The Moran Index can effectively test the spatial correlation and agglomeration of innovation quality in various regions. It includes two methods: the global Moran index and the local Moran index. The global Moran index is used to measure the aggregation state of the overall innovation quality of the space. Table 3 shows the global Moran index value of China's innovation quality from 2008 to 2017.

As can be seen from Table 3, from 2008 to 2017, the global Moran index of China's innovation quality is positive, and the $\mathrm{P}$ values are all less than 0.05 , that is, through the significance test, it reflects that the innovation quality has a positive spatial correlation. That is to say, with the agglomeration of regional spatial distribution, the correlation of innovation quality among regions becomes more obvious. This may be due to the realization of regional integration in the neighboring regions with the support of government policies.

Table 3. 2008-2017 global moran index value of China's innovation quality.

\begin{tabular}{cccccc}
\hline Year & Global Moran Index & Expectation Index & variance & $\mathrm{z}$ & $P$ \\
\hline 2008 & 0.132 & -0.033 & 0.002 & 3.348920 & 0.000811 \\
2009 & 0.121 & -0.033 & 0.002 & 3.151838 & 0.001622 \\
2010 & 0.130 & -0.033 & 0.002 & 3.323918 & 0.000888 \\
2011 & 0.137 & -0.033 & 0.002 & 3.477330 & 0.000506 \\
2012 & 0.148 & -0.033 & 0.002 & 3.688696 & 0.000225 \\
2013 & 0.173 & -0.033 & 0.002 & 4.209206 & 0.000026 \\
2014 & 0.189 & -0.033 & 0.002 & 4.528299 & 0.000006 \\
2015 & 0.141 & -0.033 & 0.002 & 3.567884 & 0.000360 \\
2016 & 0.192 & -0.033 & 0.002 & 4.624978 & 0.000004 \\
2017 & 0.184 & -0.033 & 0.002 & 4.469612 & 0.000008 \\
\hline
\end{tabular}




\section{Conclusion}

Innovation quality is the focus of research on innovation capabilities in different regions. Previous studies have focused on the number of patents as a measure of innovation capabilities. However, the increase in the number of patents can only indicate the increase in the regional $\mathrm{R} \& \mathrm{D}$ scale. To improve innovation capabilities, we should focus on the improvement of comprehensive evaluation indicators for innovation quality. Although the difference between the innovation quality of the central and western regions and the eastern region has decreased in recent years, from a practical point of view, whether it is innovation $\mathrm{R} \& \mathrm{D}$ investment or innovation quality output, the innovation quality of each region is relatively high. The large imbalance presents a spatial difference of "high in the east, weak in the east and the west". This is caused by differences in the regional economy, technology, education, and government policies. The eastern part of China has a superior geographical location, a developed economy, a concentrated area of higher scientific research institutions, and a rich reserve of innovative talents. Also, under the background of the government's active promotion of innovation quality discovery, market conditions are more mature, so the level of innovation quality is also higher. However, in the central and western regions, due to the lack of $\mathrm{R} \& \mathrm{D}$ resources and the backwardness of resources such as economy and education, the government has not provided enough support for innovation, so the quality of innovation is also low. This has also led to the slow improvement of China's overall innovation capability, which has affected the high-quality economic development. Moreover, in recent years, the quality of innovation in eastern, central, and western China has declined. Therefore, according to the results shown by the temporal and spatial differentiation of China's innovation quality, to achieve higher-quality development of China's economy, this article proposes targeted and scientific suggestions for improving the level of innovation quality in different regions.

The eastern region should make good use of the government's policy and institutional advantages. The policy should aim to increase high-quality innovation output, establish a more efficient innovation quality input-output mechanism, and further enhance the effective output of innovation, intensify the assessment of patent output and continue to increase the number of the patent output of scientific and technological projects, promote the commercialization and industrialization of scientific and technological achievements, realize the transformation of scientific and technological achievements of high-tech industries in multiple fields, increase the number of new products with high technological content, and increase the contribution rate of high-tech industries to economic growth.

The central region should establish a sound regional scientific and technological innovation system, highlight the dominant position of enterprises in innovation, focus on promoting scientific and technological collaborative innovation, increase funding and rewards for invention patent applications, and encourage enterprises to patent a large number of innovations and upgrade high technolo- 
gy Industrial innovation output capacity, adjustment of industrial structure, and expansion of the proportion of high-tech industry output value in total industrial output value. Increase investment in innovation and the introduction of scientific research talents, actively attract investment, create a good quality improvement and innovative development environment for enterprises, increase investment in scientific and technological research and development, rationally expand the scale of high-tech industries, and form a scale effect of industrial agglomeration. Besides, innovation must be "people-oriented" to establish a long-term talent incentive mechanism and talent training system to promote the development of innovation quality.

The western region is restricted by resources and regions, and the economy is underdeveloped. If the western region wants to improve its innovation quality, it should give full play to the supporting role of the government. Implement relevant policies to support regional innovation of enterprises, and attract the inflow of enterprises and talents with highly supportive attitudes and actions. By increasing the key laboratories of high-tech industries in the western region and introducing policies for high-level talents, we will increase the emphasis on and training of talents, and build the scale and quality of high-level innovative talents. Promoted by the market economy, a sound industry-university-research cooperation mechanism should be established to enhance the innovation output capacity of the western region. At the same time, we should actively explore funds, increase investment in scientific and technological research and development, and actively carry out independent research and development and imitative innovation. Also, it is necessary to improve the macroeconomic environment and institutional environment for innovation activities in the western region, increase the degree of opening up in the western region, and expand the channels for the western region to attract foreign capital and talents.

Through the establishment of a comprehensive evaluation system of innovation quality, this paper analyzes the differences of regional innovation quality in China from the perspective of time and space, enriches the theoretical research on innovation quality, and has certain practical value for improving China's innovation quality. However, the above research conclusion is based on China's provincial-level regional units. If we can adopt more detailed scale data of prefecture-level cities to carry out the research on innovation quality at the city level, we will be able to further explore the spatial and temporal differentiation of China's innovation quality, which is also the direction of further research in the future.

\section{Conflicts of Interest}

The author declares no conflicts of interest regarding the publication of this paper.

\section{References}

Haner, U. E. (2002). Innovation Quality: A Conceptual Framework. International Journal 
of Production Economics, 80, 31-37. https://doi.org/10.1016/S0925-5273(02)00240-2

Li, X. D., Li, N., Bai, J. H., et al. (2011). Research and Development of High Technology Industry Innovation Efficiency Analysis. China Soft Science, No. 2, 52-61. (In Chinese)

Liu, W. L., \& Lin, W. H. (2018). Quality of Innovation and Innovation Space Difference of Quality and Coupling Coordination Research Based on the Analysis of China's High Technology Industry Experience. Finance and Economics, No. 6, 3-10. (In Chinese)

Lu, G. Q. (2011). Research on the Performance of Industrial Innovation of China's Small and Medium-Sized Board Listed Companies. Economic Research, No. 2, 138-148. (In Chinese)

Ma, Y. H., Zhang, J. M., \& Wang, Z. Z. (2014). Analysis of Spatial Differences in Innovation Quality of High-Tech Industries in China. Economic Issues Exploration, No. 9, 89-95. (In Chinese)

Sun, Z., \& Song, W. (2012). The Effect of Enterprise R \& D Investment on Industrial Innovation Performance: Empirical Evidence from China's Manufacturing Industry. Research on the Quantitative Economy, Technology, and Economy, No. 4, 49-63+122. (In Chinese)

Tong, X., \& Frame, J. D. (1994). Measuring National Technological Performance with Patent Claims Data. Research Policy, 23, 133-141. https://doi.org/10.1016/0048-7333(94)90050-7

Yang, L. G., Miao, X. M., \& Zeng, Y. Q. (2007). Research on Innovation Quality Evaluation Model of Small and Medium-Sized High-Tech Enterprises Based on Enterprise Growth. Science and Technology Management Research, No. 6, 96-98+79. (In Chinese)

Zhang, G. P., Chen, X. D., \& Du, H.-D. (2011). China Regional Innovation Quality Inequality Study. Science Research, No. 11, 1709-1719. (In Chinese) 